\title{
lodination of carbohydrate-derived 1,2-oxazines to enantiopure 5-iodo-3,6-dihydro-2H-1,2-oxazines and subsequent palladium-catalyzed cross-coupling reactions
}

\author{
Michal Medvecký, Igor Linder, Luise Schefzig, Hans-Ulrich Reissig* \\ and Reinhold Zimmer*
}

\author{
Full Research Paper \\ Address: \\ Freie Universität Berlin, Institut für Chemie und Biochemie, \\ Takustrasse 3, D-14195 Berlin, Germany

\section{Email:} \\ Hans-Ulrich Reissig* - hans.reissig@chemie.fu-berlin.de; \\ Reinhold Zimmer* - rzimmer@zedat.fu-berlin.de \\ * Corresponding author \\ Keywords: \\ amino alcohol; click reaction; cross-coupling reactions; hydrogenation; \\ iodination; 1,2-oxazines
}

\author{
Beilstein J. Org. Chem. 2016, 12, 2898-2905. \\ doi:10.3762/bjoc. 12.289 \\ Received: 13 October 2016 \\ Accepted: 20 December 2016 \\ Published: 29 December 2016 \\ Associate Editor: J. P. Wolfe \\ (C) 2016 Medvecký et al.; licensee Beilstein-Institut. \\ License and terms: see end of document.
}

\begin{abstract}
Iodination of carbohydrate-derived 3,6-dihydro-2H-1,2-oxazines of type 3 using iodine and pyridine in DMF furnished 5-iodosubstituted 1,2-oxazine derivatives $\mathbf{4}$ with high efficacy. The alkenyl iodide moiety of 1,2-oxazine derivatives syn-4 and anti-4 was subsequently exploited for the introduction of new functionalities at the C-5 position by applying palladium-catalyzed carbon-carbon bond-forming reactions such as Sonogashira, Heck, or Suzuki coupling reactions as well as a cyanation reaction. These crosscoupling reactions led to a series of 5-alkynyl-, 5-alkenyl-, 5-aryl- and 5-cyano-substituted 1,2-oxazine derivatives being of considerable interest for further synthetic elaborations. This was exemplarily demonstrated by the hydrogenation of syn-21 and anti-24 and by a click reaction of a 5-alkynyl-substituted precursor.
\end{abstract}

\section{Introduction}

Over the last decade, we have intensively studied syntheses and applications of 3,6-dihydro-2H-1,2-oxazines of type 3 [1,2]. These N,O-heterocycles are easily prepared in enantiopure form by a stereodivergent $[3+3]$ cyclization of carbohydrate-derived nitrones 2 and lithiated alkoxyallenes 1 (Scheme 1) [3,4]. Subsequently we investigated modifications and synthetic applications of 1,2-oxazines 3 including the preparation of sevenmembered N,O-heterocycles by ring enlargement [5], functio- nalization of the enol ether unit [6-11], and N,O-cleavage reactions leading to amino alcohols $[8,10,12]$, pyrroles [13] or $\alpha, \beta$ unsaturated $\beta$-alkoxy- $\gamma$-amino-aldehydes and ketones [14]. In this context, a series of publications of our group reported on syntheses of carbohydrate mimetics [15-20] that are based on aminopyrans, aminooxepanes or other aminopolyols and that were examined for example as ligands of L- and P-selectin $[21,22]$. We previously reported the synthesis of enantiopure 
1,2-oxazin-4-yl nonaflates and phosphates starting from precursors of type 3 and their conversion into differently C-4-substituted products employing palladium-catalyzed cross-coupling reactions [23]. In a related study, we have also investigated the synthesis of 4-halogen- and 4,5-bis(halogen)-substituted $6 H-1,2$-oxazines by halogenation of $6 H-1,2$-oxazines and subsequent palladium-catalyzed coupling reactions such as Sonogashira or Suzuki-Miyaura reactions [24] leading to aryl- and alkynyl-functionalized products. The synthetic potential of the mono- and bisalkynyl-substituted $6 H-1,2$-oxazines was additionally demonstrated by Lewis-acid-mediated conversion into highly substituted pyridine derivatives [25] by cycloaddition of in situ generated azapyrylium intermediates [26] and alkynes. Inspired by these previously reported results, we focused our interest on the so far unknown functionalization at the C-5 position of the synthetically useful enantiopure 3,6-dihydro-1,2oxazines 3. Herein, we now disclose our results on the iodination of 3 to provide the previously undescribed 5-iodo-1,2oxazine derivatives 4 . These new intermediates allow subsequent $\mathrm{C}-\mathrm{C}$ functionalization at the $\mathrm{C}-5$ position employing various palladium-catalyzed cross-coupling reactions thus expanding the library of available enantiopure 3,6-dihydro- $2 \mathrm{H}$ 1,2-oxazines.

$$
{ }_{1}^{1}
$$

Scheme 1: Access to enantiopure 3,6-dihydro-1,2-oxazines 3 via lithiated alkoxyallenes $\mathbf{1}$ and carbohydrate-derived nitrones $\mathbf{2}$.

\section{Results and Discussion}

Numerous procedures exist for the synthesis of $\beta$-iodo enol ethers [27], although the direct $\beta$-iodination of enol ethers using a suitable electrophilic iodine reagent is relatively underdeveloped. For the iodination of 4-alkoxy-3,6-dihydro-1,2-oxazines 3 , we selected molecular iodine as the most simple iodination reagent in the presence of a base [28-30]. A clean reaction occurred upon treatment of D-glyceraldehyde-derived synconfigured 3,6-dihydro-1,2-oxazines syn-3a-c with three equivalents of iodine and one equivalent of pyridine as base in DMF at room temperature giving the desired 5-iodo-substituted 1,2oxazines syn-4a-c in 55-87\% yield after purification by column chromatography (Scheme 2). This operationally simple iodination protocol was also successfully applied to the anti-configured 1,2-oxazine anti-3a and the D-arabinose-derived starting material anti-3d furnishing the expected iodinated products anti-4a and anti-4d in good yields.

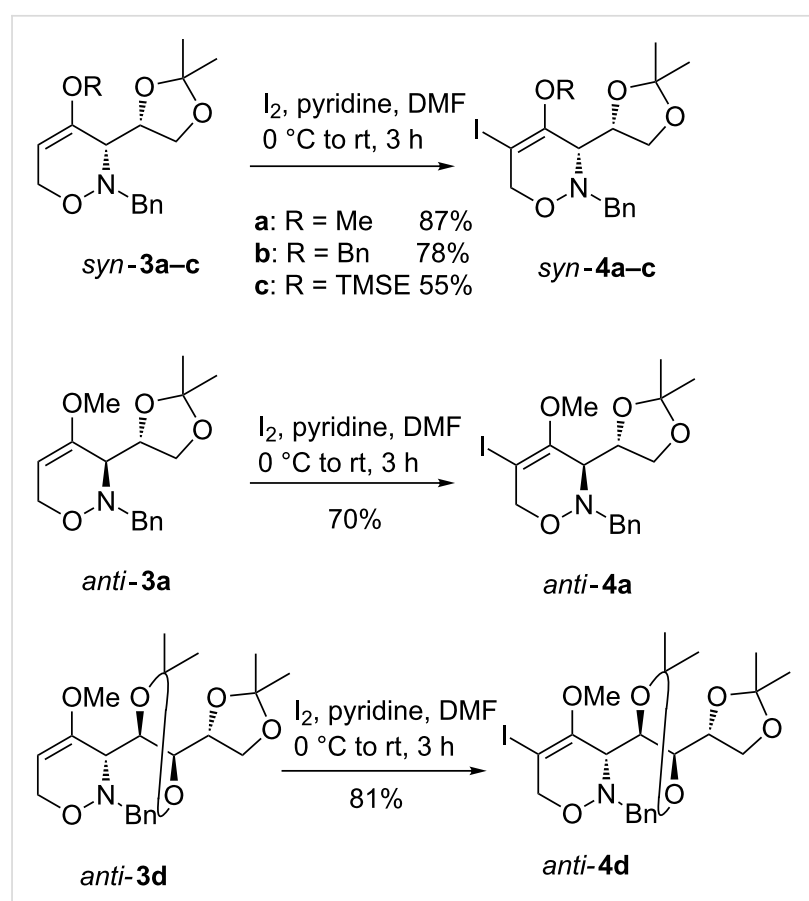

Scheme 2: lodination of 1,2-oxazines syn-3a-c and anti-3a,d leading to 5 -iodo-substituted 1,2-oxazines syn-4a-c and anti-4a,d [TMSE = (2-trimethylsilyl)ethyl].

Having attained an access to 5-iodo-substituted 1,2-oxazines $\mathbf{4}$, we turned our attention to their conversion into subsequent products by taking advantage of the alkenyl iodide functionality for various palladium-catalyzed cross-coupling reactions. As a first approach to form a new $\mathrm{C}-\mathrm{C}$ bond at $\mathrm{C}-5$ we envisioned the Sonogashira coupling. For this purpose, we selected (trimethylsilyl)acetylene as alkyne component. The Sonogashira couplings of 5-iodo-1,2-oxazines syn-4a and anti-4a were carried out under standard conditions using a catalytic system consisting of $\mathrm{PdCl}_{2}\left(\mathrm{PPh}_{3}\right)_{2}, \mathrm{CuI}$ and triethylamine in toluene at room temperature to furnish the corresponding 5-(trimethylsilyl)ethynyl-substituted 1,2-oxazines syn-5 and anti-5 in good yields (Scheme 3). When these reaction conditions were applied to the D-arabinose-derived 5-iodo-1,2-oxazine anti-4d, the desired coupling product anti-6 was formed merely in $28 \%$ yield. Gratifyingly, this transformation was considerably improved when an alternative coupling protocol $\left(\mathrm{Pd}(\mathrm{OAc})_{2}, \mathrm{PPh}_{3}\right.$, $\mathrm{CuI}$ in $\mathrm{NEt}_{3} / \mathrm{DMF}$ ) was employed, the yield was significantly enhanced and the coupling product anti-6 was obtained in 59\% yield.

Sonogashira couplings of 4-benzyloxy- and 4-(2-trimethylsilyl)ethoxy-substituted 1,2-oxazines syn-4b and syn-4c with phenylacetylene worked equally well and provided under the standard conditions the desired phenylethynyl-substituted products $s y n-7$ and $s y n-8$, respectively, in comparable yields (Scheme 4). Even the unprotected propargyl alcohol could be 
<smiles>COC1=C(I)CON(Cc2ccccc2)C1C1CCC(C)(C)O1</smiles>

syn-4a<smiles>COC1=C(I)CON(Cc2ccccc2)C1C1COC(C)(C)O1</smiles>

anti-4a<smiles>COC1=C(I)CON(Cc2ccccc2)[C@H]1[C@H](OC(C)(C)C)C(=O)C1COC(C)(C)O1</smiles>

anti-4d $\equiv \mathrm{SiMe}_{3}$

$\mathrm{PdCl}_{2}\left(\mathrm{PPh}_{3}\right)_{2}, \mathrm{Cul}, \mathrm{Et}_{3} \mathrm{~N}$

toluene, rt, $16 \mathrm{~h}$

$75 \%$

$\equiv \mathrm{SiMe}_{3}$

$\mathrm{PdCl}_{2}\left(\mathrm{PPh}_{3}\right)_{2}, \mathrm{Cul}, \mathrm{Et}_{3} \mathrm{~N}$

toluene, $\mathrm{rt}, 16 \mathrm{~h}$

$73 \%$

$\equiv \mathrm{SiMe}_{3}$

$\mathrm{Pd}(\mathrm{OAc})_{2}, \mathrm{PPh}_{3}$, Cul

$\mathrm{Et}_{3} \mathrm{~N}, \mathrm{DMF}, \mathrm{rt}, 18 \mathrm{~h}$

$59 \%$<smiles>COC1=C(C#C[SiH2]C)CON(Cc2ccccc2)[C@H]1[C@H]1COC(C)(C)O1</smiles>

syn-5<smiles>COC1=C(C#C[SiH2]C)CON(Cc2ccccc2)C1[C@H]1COC(C)(C)O1</smiles>

anti-5<smiles>COC1=C(C#C[SiH2]C)CON[C@H]1[C@H](OC(C)(C)C)C(=O)C1COC(C)(C)O1</smiles>

anti- 6

Scheme 3: Sonogashira reactions of 4-methoxy-1,2-oxazines syn-4a, anti-4a and anti-4d leading to 5-alkynyl-substituted 1,2-oxazines syn-5, anti-5 and anti-6.

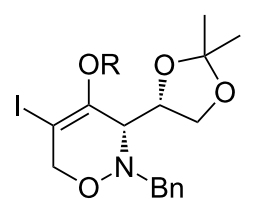

\section{$\mathrm{PdCl}_{2}\left(\mathrm{PPh}_{3}\right)_{2}, \mathrm{Cul}, \mathrm{Et}_{3} \mathrm{~N}$ toluene, rt, $16 \mathrm{~h}$}

syn-4b,c<smiles>COC1=C(I)CON(Cc2ccccc2)[C@@H]1[C@H]1COC(C)(C)O1</smiles>

syn-4a<smiles>COC1=C(I)CON(Cc2ccccc2)[C@@H]1[C@H]1COC(C)(C)O1</smiles>

syn-4a<smiles>[R]OC1=C(C#Cc2ccccc2)CON(Cc2ccccc2)[C@@H]1[C@H]1COC(C)(C)O1</smiles>

syn-7

syn- 8<smiles>COC1=C(C#CCO)CON(Cc2ccccc2)[C@H]1[C@H]1COC(C)(C)O1</smiles>

syn-9<smiles>COC1=C(C#Cc2c(-c3ccccc3)nc(C)n2-c2ccccc2)CON(Cc2ccccc2)C1C1COC(C)(C)O1</smiles>

syn-11

Scheme 4: Sonogashira reactions of D-glyceraldehyde-derived 1,2-oxazines syn-4a-c leading to 5-alkynyl-substituted 1,2-oxazines syn-7, syn-8, syn-9 and syn-11.

applied under these coupling conditions affording the corresponding 5-alkynyl-substituted 1,2-oxazine syn-9, albeit in moderate yield (52\%). In the last example of Scheme 4, syn-4a was coupled with an imidazolyl-substituted alkyne 10, that also derives from lithiated methoxyallene [31] and that was already successfully applied as alkyne component in other Sonogashira 
couplings presented in former publications $[23,32]$. The reaction of syn-4a and alkyne $\mathbf{1 0}$ using palladium acetate, triphenylphosphine, and copper(I) iodide in a solvent mixture of diisopropylamine and DMF at room temperature gave the 5-(imidazolylethynyl)-substituted 1,2-oxazine syn-11 in 41\% yield.

Next, we briefly studied 5-iodo-1,2-oxazine syn-4a as substrate in Heck reactions. The substrate was reacted with the alkyl acrylates $\mathbf{1 2} \mathbf{a}\left(\mathrm{R}^{1}=\mathrm{Me}\right)$ and $\mathbf{1 2 b}\left(\mathrm{R}^{1}=t\right.$-Bu) under phosphinefree conditions $[33,34]$ using $6 \mathrm{~mol} \%$ of palladium(II) acetate, triethylamine as base and lithium chloride [35] leading to the expected coupling products syn-13 and syn-14 in 39\% and 82\% yield, respectively (Scheme 5). In both cases, only the $E$-configured 2-substituted alkyl acrylates were isolated. The moderate yield in the Heck reaction with methyl acrylate 12a is very likely caused by the tendency of this olefin to polymerize under the conditions applied. Consequently, the change of the olefin component from the methyl to the tert-butyl ester allowed the preparation of the corresponding coupling product syn-14 in significantly better yield. The use of dehydroamino acids such as olefin 16 [36] in Heck reactions [37-42] is also of interest, since these coupling products are useful intermediates for the synthesis of non-proteinogenic amino acids [43]. To our delight, the Heck coupling of syn-4a and $\mathbf{1 6}$ could be efficiently achieved employing Jeffery's conditions [44]. When the coupling was performed using palladium(II) acetate, solid $\mathrm{NaHCO}_{3}$ and tetra- $n$-butylammonium bromide (TBAB) at $130{ }^{\circ} \mathrm{C}$ $[37,38,42]$ the desired $\beta-1,2$-oxazinyl-substituted dehydroamino acid derivative $s y n-17$ was obtained in $69 \%$ yield. We did not prove the $Z$-configuration of the external $\mathrm{C}=\mathrm{C}$ bond, since it is well documented that in related cross-coupling reactions of 16 exclusively the $Z$-isomers are formed [40].
The 5-iodo-1,2-oxazines syn-4a,b reacted smoothly under standard conditions of Suzuki-Miyaura coupling reactions [45] with vinylboronic acid $\mathbf{1 8}$ and 3-methoxyphenylboronic acid $\mathbf{2 0}$ to furnish the expected 5-styryl-substituted derivative syn-19 and the 5-aryl-substituted derivatives $s y n-21$ and $s y n-22$, respectively, in moderate to good yield (Scheme 6). Notably, the D-arabinose-derived 5-iodo-1,2-oxazine anti-4d was also efficiently converted into the 5-phenyl-substituted compound anti-24 employing phenylboronic acid $\mathbf{2 3}$ under the same reaction conditions in excellent yield.

In the last example of palladium-catalyzed reactions, we set out to prove a 5-iodo-1,2-oxazine $\mathbf{4}$ as substrate in a cyanation reaction that would lead to a 5-cyano-substituted derivative. The installation of a cyano group at the 5-position would lead to a push-pull system that could open new synthetic opportunities including the attack of nucleophiles at C-4. Metal cyanides such as $\mathrm{KCN}$ represent synthetically valuable $\mathrm{C}-1$ building blocks that could efficiently be coupled by palladium catalysis to alkenyl triflates $[46,47]$ or alkenyl halides $[48,49]$ forming $\alpha, \beta-$ unsaturated nitriles. As shown in Scheme 7, we adopted a protocol described by Yamamura and Murahashi [48] and found that the palladium-catalyzed coupling of anti-4d with potassium cyanide in the presence of 18 -crown- 6 at $80{ }^{\circ} \mathrm{C}$ in toluene afforded the desired 5-cyano-substituted product anti-25 in moderate yield (not optimized).

The synthetic usefulness of the obtained 5-alkynyl-, 5-alkenyland 5-aryl-substituted 1,2-oxazine derivatives depends on their ability to undergo subsequent transformations. Due to their high degree of functionalization, the C-5-substituted 1,2-oxazine derivatives prepared by the coupling reactions described above

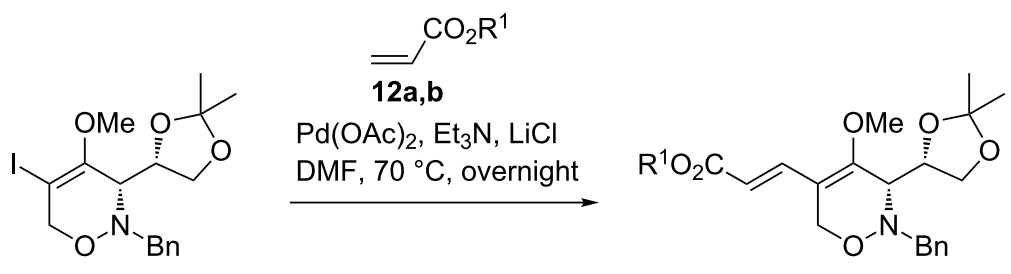

$$
\text { syn-4a }
$$<smiles>COC1=C(I)CON(Cc2ccccc2)[C@H]1C1COC(C)(C)O1</smiles>

syn-4a

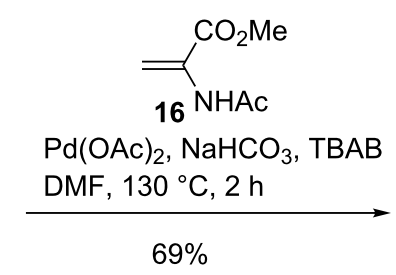

$69 \%$ syn-13 $\left(\mathrm{R}^{1}=\mathrm{Me}\right) 39 \%$

syn-14 $\left(\mathrm{R}^{1}=t-\mathrm{Bu}\right) 82 \%$

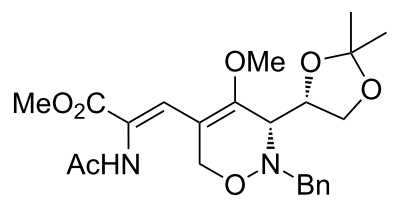

syn-17 
<smiles>COC1=C(I)CON(Cc2ccccc2)[C@H]1[C@H]1COC(C)(C)O1</smiles>

syn-4a

$$
\mathrm{Ph} / \mathrm{B}(\mathrm{OH})_{2}
$$

18

$\mathrm{Pd}(\mathrm{OAc})_{2}, \mathrm{PPh}_{3}, \mathrm{~K}_{2} \mathrm{CO}_{3}$

DMF, $80^{\circ} \mathrm{C}$, overnight

$50 \%$<smiles>COc1cccc(Br)c1</smiles>

20<smiles>[R]OC1=C(I)CON(Cc2ccccc2)[C@H]1[C@H]1COC(C)(C)O1</smiles>

$\mathrm{Pd}(\mathrm{OAc})_{2}, \mathrm{PPh}_{3}, \mathrm{~K}_{2} \mathrm{CO}_{3}$ DMF, $80^{\circ} \mathrm{C}$, overnight<smiles>COC1=C(/C=C/c2ccccc2)CON(Cc2ccccc2)[C@@H]1[C@H]1COC(C)(C)O1</smiles>

syn-19<smiles>[R]OC1=C(c2cccc(OC)c2)CON(Cc2ccccc2)[C@H]1[C@H]1COC(C)(C)O1</smiles>

syn-21 $(\mathrm{R}=\mathrm{Me}) \mathbf{7 6} \%$

syn-22 $(\mathrm{R}=\mathrm{Bn}) \mathbf{8 2} \%$<smiles>COC1=C(c2ccccc2)CON(Br)[C@H]1[C@H](OC(C)(C)C)C(=O)C1COC(C)(C)O1</smiles>

anti-24

Scheme 6: Suzuki-Miyaura reactions of 1,2-oxazines syn-4a, syn-4b and anti-4d leading to 5-styryl-substituted 1,2-oxazine syn-19 and 5-aryl-substituted 1,2-oxazines syn-21, syn-22 and anti-24.<smiles>COC1=C(I)CON2C(=O)C1C(C(=O)C1COC(C)(C)O1)C2(C)C</smiles>

anti-4d
$\mathrm{KCN}, \mathrm{Pd}\left(\mathrm{PPh}_{3}\right)_{4}, 18-$ crown-6 toluene, $80^{\circ} \mathrm{C}, 5 \mathrm{~h}$

$52 \%$<smiles>COC1=C(C#N)CONC1C(=O)C1COC(C)(C)O1</smiles>

anti-25

Scheme 7: Cross-coupling reaction of 1,2-oxazine anti-4d leading to 5-cyano-substituted 1,2-oxazine anti-25.

should be versatile precursors for a variety of subsequent reactions, e.g., acid-catalyzed hydrolysis, hydrogenations or cyclization reactions. For example, we envisioned that 3,6-dihydro- $2 H$ 1,2-oxazines bearing the newly installed alkynyl group at $\mathrm{C}-5$ are ideal candidates for efficient subsequent transformations. A very popular and widely applied reaction of terminal alkynes is the copper-catalyzed azide-alkyne cycloaddition, also termed as click reaction, efficiently leading to 1,4-disubstituted 1,2,3-triazoles [50]. After the desilylation of syn-5 using potassium fluoride in methanol (Scheme 8) the resulting mono-substituted alkyne was subjected to an established protocol using benzyl azide, copper(I) iodide, triethylamine and TBTA [51] (for a recent review see [52]). The cycloaddition proceeded well and afforded the expected 5-(1,2,3-triazolyl)-substituted 1,2-oxazine syn-26 in moderate yield (54\%).

Hydrogenolysis belongs to the well-established transformations of 1,2-oxazines, often successfully leading to valuable compounds including 1,4-amino alcohols or pyrrolidine derivatives. We therefore briefly examined the reaction of 5-aryl-substituted 1,2-oxazines syn-21 and anti-24 under previously established conditions [53]. The hydrogenolysis of 1,2-oxazine derivative $s y n-\mathbf{2 1}$ in methanol using palladium on charcoal as catalyst afforded the expected $\alpha$-(3-methoxyphenyl)-substituted 
<smiles>COC1=C(C#C[SiH2]C)CON(Cc2ccccc2)C1C1COC(C)(C)O1</smiles>

syn-5 a) $\mathrm{KF}, \mathrm{MeOH}, \mathrm{THF}, \mathrm{rt}, 24 \mathrm{~h}$ $76 \%$

b) $\mathrm{BnN}_{3}, \mathrm{Et}_{3} \mathrm{~N}, \mathrm{TBTA}$, Cul $\mathrm{MeCN}, \mathrm{rt}, 1 \mathrm{~d}$

$54 \%$<smiles>COC1=C(c2cn(Cc3ccccc3)nn2)CON(Cc2ccccc2)[C@H]1[C@H]1COC(C)(C)O1</smiles>

syn-26

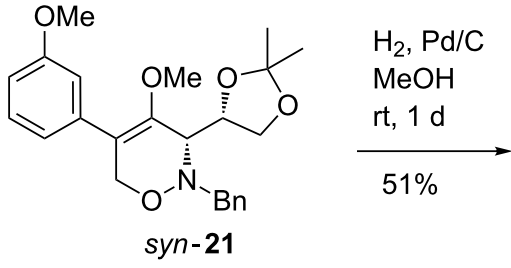<smiles>COc1cccc([C@H](CO)[C@H](N)[C@H](OC)[C@H]2COC(C)(C)O2)c1</smiles>

$(96: 4)$<smiles>COc1cccc(C(CO)[C@H](OC)[C@H](N)C2COC(C)(C)O2)c1</smiles>

$\mathrm{MsCl}, \mathrm{Et}_{3} \mathrm{~N}, \mathrm{CH}_{2} \mathrm{Cl}_{2}$

rt, $2 \mathrm{~h}$

$65 \%$

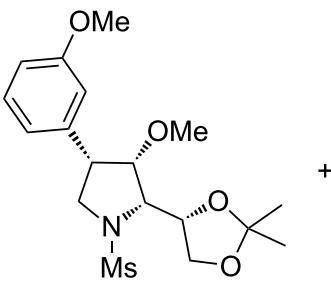

28a

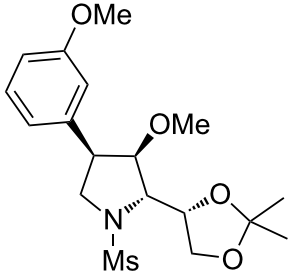

28b

Scheme 9: Hydrogenation of 1,2-oxazine syn-21 leading to $\mathrm{Y}$-amino alcohols $\mathbf{2 7 a} \mathbf{a} \mathbf{b}$ and subsequent ring closure to pyrrolidine derivatives $\mathbf{2 8 a , \mathbf { b }}$.

$\gamma$-amino alcohol derivative 27 in 51\% yield as $96: 4$ mixture of two diastereomers (Scheme 9). Subsequent ring closure of $\gamma$-amino alcohol 27 by treatment with mesyl chloride in the presence of triethylamine [53] furnished the $N$-mesylated pyrrolidine derivative $\mathbf{2 8}$ in $65 \%$ yield with excellent diastereoselectivity (dr 95:5).

In contrast, when these hydrogenolysis conditions were applied to the D-arabinose-derived 5-phenyl-1,2-oxazine anti-24 merely an inseparable complex mixture of products was obtained. After shortening of the reaction time from one day to one hour, we were able to isolate two products, the $N$-debenzylated 3,6dihydro- $2 H$-1,2-oxazine anti-29 in 37\% yield and the 3,4,5,6tetrahydro- $2 H-1,2-$ oxazine anti-30 in $36 \%$ yield as a $93: 7$ mixture of diastereomers (Scheme 10). The dependence of product distribution, especially in the latter case, revealed that a specif- ic reaction sequence is operating during the hydrogenolysis processes. As already discussed in previous publications [23,53], the hydrogenolysis of 1,2-oxazines of type 3 with palladium on charcoal very likely starts with a fast $N$-debenzylation, followed by the reduction of the $\mathrm{C}-4 / \mathrm{C}-5$ double bond forming the corresponding 3,4,5,6-tetrahydro- $2 H$-1,2-oxazines that after cleavage of the $\mathrm{N}-\mathrm{O}$ bond provide the corresponding amino alcohols. In the second reaction step, the hydrogen attacks the $\mathrm{C}=\mathrm{C}$ bond mainly from the less hindered side (here trans to the fairly bulky 3-dioxolanyl group) leading to the preferred configuration of anti-30a as depicted in Scheme 10.

The three successful transformations demonstrate the potential of 1,2-oxazines with substituents at C-5 for further elaborations, they also show that careful optimizations are required in each individual case, in particular for the hydrogenolysis reactions. 


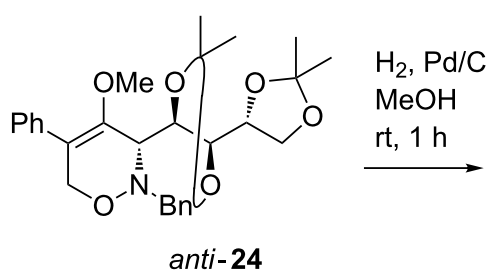

anti-24

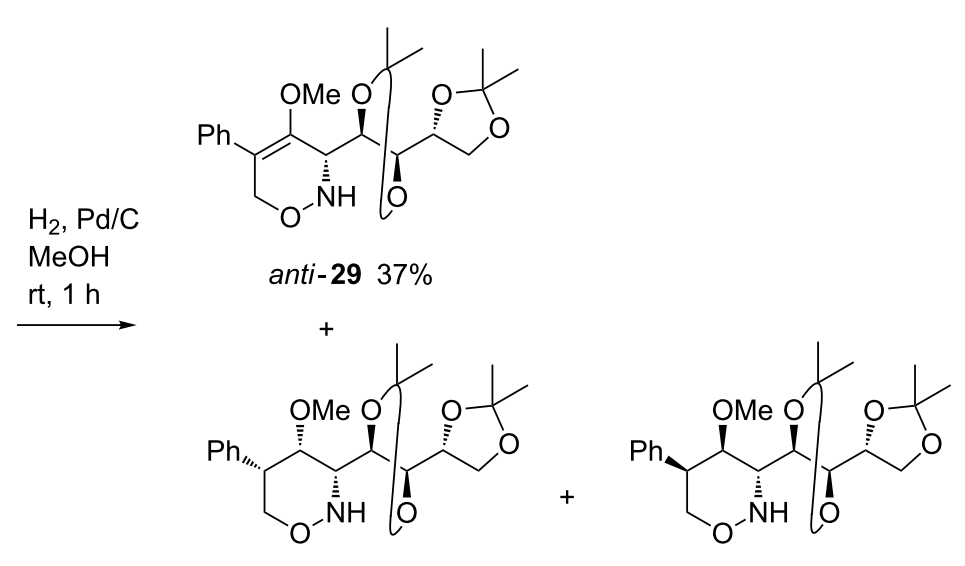

anti-30a

anti-30b

Scheme 10: Hydrogenation of 1,2-oxazine anti-24 to products anti-29 and anti-30.

\section{Conclusion}

We have demonstrated that the enol ether unit of 3,6-dihydro$2 H$-1,2-oxazines 3 can efficiently be converted into the corresponding 5-iodo-substituted compounds $\mathbf{4}$ under mild reaction conditions using molecular iodine in the presence of pyridine as base. The obtained alkenyl iodides $\mathbf{4}$ are ideal candidates for further transformations. As shown in this report, the subsequent cross-coupling reactions at $\mathrm{C}-5$ position considerably broaden the scope of available 3,6-dihydro- $2 H$-1,2-oxazines that are highly functionalized and have high potential for further synthetic elaborations, in particular for the preparation of enantiopure acyclic and cyclic amino alcohols.

\section{Supporting Information}

\section{Supporting Information File 1}

General information, all experimental procedures and analytical data.

[http://www.beilstein-journals.org/bjoc/content/ supplementary/1860-5397-12-289-S1.pdf]

\section{Supporting Information File 2}

Copies of ${ }^{1} \mathrm{H}$ and ${ }^{13} \mathrm{C}$ NMR spectra of compounds 4-9, 11,

\section{4, 19, 21, 24-27, 29 and 30.}

[http://www.beilstein-journals.org/bjoc/content/ supplementary/1860-5397-12-289-S2.pdf]

\section{Acknowledgements}

This work was generously supported by the Deutsche Forschungsgemeinschaft and by Bayer HealthCare. We acknowledge valuable discussions with Dr. Léa Bouché and Dr. Maja Kandziora. We also thank Thomas Gries, Johannes Matting and Jacob Mayer for their experimental assistance.

\section{References}

1. Brasholz, M.; Reissig, H.-U.; Zimmer, R. Acc. Chem. Res. 2009, 42, 45-56. doi:10.1021/ar800011h

2. Zimmer, R.; Reissig, H.-U. Chem. Soc. Rev. 2014, 43, 2888-2903. doi:10.1039/c3cs60429b

3. Schade, W.; Reissig, H.-U. Synlett 1999, 632-634. doi:10.1055/s-1999-2662

4. Helms, M.; Schade, W.; Pulz, R.; Watanabe, T.; Al-Harrasi, A.; Fišera, L.; Hlobilová, I.; Zahn, G.; Reissig, H.-U. Eur. J. Org. Chem. 2005, 1003-1019. doi:10.1002/ejoc.200400627

5. Al-Harrasi, A.; Fischer, S.; Zimmer, R.; Reissig, H.-U. Synthesis 2010, 304-314. doi:10.1055/s-0029-1217126

6. Pulz, R.; Al-Harrasi, A.; Reissig, H.-U. Org. Lett. 2002, 4, 2353-2355. doi:10.1021/ol0260573

7. Dekaris, V.; Reissig, H.-U. Synlett 2010, 42-46. doi:10.1055/s-0029-1218531

8. Dekaris, V.; Pulz, R.; Al-Harrasi, A.; Lentz, D.; Reissig, H.-U. Eur. J. Org. Chem. 2011, 3210-3219. doi:10.1002/ejoc.201100230

9. Jasiński, M.; Lentz, D.; Reissig, H.-U. Beilstein J. Org. Chem. 2012, 8, 662-674. doi:10.3762/bjoc.8.74

10. Jasiński, M.; Moreno-Clavijo, E.; Reissig, H.-U. Eur. J. Org. Chem. 2014, 442-454. doi:10.1002/ejoc.201301406

11. Jasiński, M.; Utecht, G.; Fruziński, A.; Reissig, H.-U. Synthesis 2016, 48, 893-905. doi:10.1055/s-0035-1560398

12. Parmeggiani, C.; Cardona, F.; Giusti, L.; Reissig, H.-U.; Goti, A. Chem. - Eur. J. 2013, 19, 10595-10604. doi:10.1002/chem.201301320

13. Jasiński, M.; Watanabe, T.; Reissig, H.-U. Eur. J. Org. Chem. 2013, 605-610. doi:10.1002/ejoc.201201210

14. Al-Harrasi, A.; Bouché, L.; Zimmer, R.; Reissig, H.-U. Synthesis 2011, 109-118. doi:10.1055/s-0030-1258326

15. Bouché, L.; Reissig, H.-U. Pure Appl. Chem. 2012, 84, 23-36. doi:10.1351/PAC-CON-11-09-20

16. Bouché, L.; Kandziora, M.; Reissig, H.-U. Beilstein J. Org. Chem. 2014, 10, 213-223. doi:10.3762/bjoc.10.17

17. Bouché, L.; Reissig, H.-U. Eur. J. Org. Chem. 2014, 3697-3703. doi:10.1002/ejoc.201402191

18. Kandziora, M.; Reissig, H.-U. Beilstein J. Org. Chem. 2014, 10, 1749-1758. doi:10.3762/bjoc. 10.182 
19. Kandziora, M.; Reissig, H.-U. Eur. J. Org. Chem. 2015, 370-377. doi:10.1002/ejoc.201403186

20. Kandziora, M.; Mucha, E.; Zucker, S. P.; Reissig, H.-U. Synlett 2015, 26, 367-374. doi:10.1055/s-0034-1379503

21. Dernedde, J.; Enders, S.; Reissig, H.-U.; Roskamp, M.; Schlecht, S.; Yekta, S. Chem. Commun. 2009, 932-934. doi:10.1039/b818263a

22. Roskamp, M.; Enders, S.; Pfrengle, F.; Yekta, S.; Dekaris, V.; Dernedde, J.; Reissig, H.-U.; Schlecht, S. Org. Biomol. Chem. 2011, 9, 7448-7456. doi:10.1039/c1ob05583f

23. Moinizadeh, N.; Klemme, R.; Kansy, M.; Zimmer, R.; Reissig, H.-U. Synthesis 2013, 45, 2752-2762. doi:10.1055/s-0033-1339509

24. Zimmer, R.; Schmidt, E.; Andrä, M.; Duhs, M.-A.; Linder, I.; Reissig, H.-U. Beilstein J. Org. Chem. 2009, 5, No. 44. doi:10.3762/bjoc.5.44

25. Linder, I.; Gerhard, M.; Schefzig, L.; Andrä, M.; Bentz, C.; Reissig, H.-U.; Zimmer, R. Eur. J. Org. Chem. 2011, 6070-6077. doi:10.1002/ejoc.201100765

26. Zimmer, R.; Reissig, H.-U.; Homann, K. J. Prakt. Chem. 1995, 337, 521-528. doi:10.1002/prac. 199533701112

27. Nubbemeyer, U. Sci. Synth. 2008, 32, 169-200.

28. Sha, C.-K.; Shen, C.-Y.; Jean, T.-S.; Chiu, R.-T.; Tseng, W.-H. Tetrahedron Lett. 1993, 34, 7641-7644. doi:10.1016/S0040-4039(00)60422-7

29. Paintner, F. F.; Allmendinger, L.; Bauschke, C. Synlett 2005, 2735-2738. doi:10.1055/s-2005-918915

30. Hanessian, S.; Focken, T.; Oza, R. Org. Lett. 2010, 12, 3172-3175. doi:10.1021/ol101103q

31. Gwiazda, M.; Reissig, H.-U. Synthesis 2008, 990-994. doi:10.1055/s-2007-990933

32. Lechel, T.; Dash, J.; Brüdgam, I.; Reissig, H.-U. Eur. J. Org. Chem. 2008, 3647-3655. doi:10.1002/ejoc.200800398

33. Voigt, K.; von Zezschwitz, P.; Rosauer, K.; Lansky, A.; Adams, A.; Reiser, O.; de Meijere, A. Eur. J. Org. Chem. 1998, 1521-1534. doi:10.1002/(SICI)1099-0690(199808)1998:8<1521::AID-EJOC1521>3 .0.CO;2-E

34. Lyapkalo, I. M.; Webel, M.; Reissig, H.-U. Eur. J. Org. Chem. 2001, 4189-4194. doi:10.1002/1099-0690(200111)2001:22<4189::AID-EJOC4189>3.0.C $0 ; 2-1$

35. Merlic, C. A.; Semmelhack, M. F. J. Organomet. Chem. 1990, 391, C23-C27. doi:10.1016/0022-328X(90)80183-Z

36. Crestey, F.; Collot, V.; Stiebing, S.; Rault, S. Synthesis 2006, 3506-3514. doi:10.1055/s-2006-950242

37. Carlström, A.-S.; Frejd, T. Synthesis 1989, 414-418. doi:10.1055/s-1989-27270

38. Carlström, A.-S.; Frejd, T. Acta Chem. Scand. 1992, 46, 163-171. doi:10.3891/acta.chem.scand.46-0163

39. Arcadi, A.; Cacchi, S.; Marinelli, F.; Morera, E.; Ortar, G. Tetrahedron 1990, 46, 7151-7164. doi:10.1016/S0040-4020(01)87897-2

40. Yokoyama, Y.; Takahashi, M.; Takashima, M.; Kohno, Y.; Kobayashi, H.; Kataoka, K.; Shidori, K.; Murakami, Y. Chem. Pharm. Bull. 1994, 42, 832-838. doi:10.1248/cpb.42.832

41. de Azambuja, F.; Duarte Correia, C. R. Tetrahedron Lett. 2011, 52, 42-45. doi:10.1016/j.tetlet.2010.10.132

42. Bozell, J. J.; Vogt, C. E.; Gozum, J. J. Org. Chem. 1991, 56, 2584-2587. doi:10.1021/jo00007a060

43. Taszarek, M.; Reissig, H.-U. ChemistrySelect 2016, 1, 5712-5714. doi:10.1002/slct.201601241

44. Ajana, W.; Feliu, L.; Alvarez, M.; Joule, J. A. Tetrahedron 1998, 54, 4405-4412. doi:10.1016/S0040-4020(98)00154-9
45. Miyaura, N.; Suzuki, A. Chem. Rev. 1995, 95, 2457-2483. doi:10.1021/cr00039a007

46. Quirante, J.; Escolano, C.; Massot, M.; Bonjoch, J. Tetrahedron 1997, 53, 1391-1402. doi:10.1016/S0040-4020(96)01051-4

47. Hübner, H.; Haubmann, C.; Utz, W.; Gmeiner, P. J. Med. Chem. 2000, 43, 756-762. doi:10.1021/jm991098z

48. Yamamura, K.; Murahashi, S.-I. Tetrahedron Lett. 1977, 18, 4429-4430. doi:10.1016/S0040-4039(01)83527-9

49. Piers, E.; Fleming, F. F. Can. J. Chem. 1993, 71, 1867-1872. doi:10.1139/v93-234

50. Singh, M. S.; Chowdhury, S.; Koley, S. Tetrahedron 2016, 72, 5257-5283. doi:10.1016/j.tet.2016.07.044

51. Wang, Q.; Chan, T. R.; Hilgraf, R.; Fokin, V. V.; Sharpless, K. B.; Finn, M. G. J. Am. Chem. Soc. 2003, 125, 3192-3193. doi:10.1021/ja021381e

52. Haldón, E.; Nicasio, M. C.; Pérez, P. J. Org. Biomol. Chem. 2015, 13, 9528-9550. doi:10.1039/C5OB01457C

53. Pulz, R.; Watanabe, T.; Schade, W.; Reissig, H.-U. Synlett 2000, 983-986. doi:10.1055/s-2000-6654

\section{License and Terms}

This is an Open Access article under the terms of the Creative Commons Attribution License (http://creativecommons.org/licenses/by/4.0), which permits unrestricted use, distribution, and reproduction in any medium, provided the original work is properly cited.

The license is subject to the Beilstein Journal of Organic Chemistry terms and conditions:

(http://www.beilstein-journals.org/bjoc)

The definitive version of this article is the electronic one which can be found at: doi:10.3762/bjoc. 12.289 